\title{
Central Precocious Puberty due to Hypothalamic Hamartomas Correlates with Anatomic Features but Not with Expression of GnRH, TGF $\alpha$, or KISS1
}

\author{
Yee-Ming Chan ${ }^{a}$ b Kristina A. Fenoglio-Simeone ${ }^{c}$ Sophia Paraschos ${ }^{a}$ \\ Laura Muhammad $^{c}$ Matthew M. Troester ${ }^{c}$ Yu-tze $\mathrm{Ng}^{c}$ \\ Roger E. Johnsonbaugh ${ }^{d}$ Stephen W. Coons ${ }^{e}$ Erin C. Prenger ${ }^{f}$ \\ John F. Kerrigan, Jr. ${ }^{c}$ Stephanie B. Seminara ${ }^{a}$ \\ ${ }^{a}$ Harvard Reproductive Sciences Center and Reproductive Endocrine Unit, Department of Medicine, \\ Massachusetts General Hospital and b Division of Endocrinology, Department of Medicine, Children's Hospital \\ Boston, Boston, Mass., 'Divisions of Neurology and Pediatric Neurology, Barrow Neurological Institute and \\ Children's Health Center, St. Joseph's Hospital and Medical Center, ${ }^{d}$ Arizona Pediatric Endocrinology, and Divisions \\ of ${ }^{\mathrm{N}}$ Neuropathology and ${ }^{\mathrm{f}}$ Neuroimaging, Barrow Neurological Institute, Phoenix, Ariz., USA
}

\section{Key Words}

Kisspeptin · KISS1R • GPR54 • Reproduction · LHRH •

Hypothalamic hamartoma

\begin{abstract}
Background/Aims: Hypothalamic hamartomas are the most common identifiable cause of central precocious puberty (CPP). Hamartoma characteristics proposed to be associated with CPP include specific anatomic features and expression of molecules such as gonadotropin-releasing hormone $(\mathrm{GnRH})$, transforming growth factor $\alpha(\mathrm{TGF} \alpha)$, and GRM1A, which encodes the type 1 metabotropic glutamate receptor $\alpha$ isoform. We sought to determine whether hamartomas that cause CPP could be distinguished by anatomic features, expression of these molecules, or expression of KISS1, whose products signal through the receptor GPR54 to stimulate $\mathrm{GnRH}$ release. Methods: Clinical records and radiologic images were reviewed for 18 patients who underwent hamartoma resection for intractable seizures; 7 had precocious puberty. Resected tissue was examined for expression of $\mathrm{GnRH}$, $\mathrm{GnRH}$ receptor (GnRHR), TGF $\alpha, K I S S 1$, GPR54, and GRM1A.
\end{abstract}

\section{KARGER}

(C) 2010 S. Karger AG, Basel

Fax +41613061234 E-Mail karger@karger.ch www.karger.com www.karger.com/hrp
Results: Hypothalamic hamartomas associated with CPP were more likely to contact the infundibulum or tuber cinereum and were larger than hamartomas not associated with CPP. GnRH, TGF $\alpha$, and GnRHR were expressed by all hamartomas studied. Expression of KISS1, GPR54, and GRM1A did not differ significantly between hamartomas associated and not associated with CPP. Conclusion: Anatomic features rather than expression patterns of candidate molecules distinguish hypothalamic hamartomas that are associated with CPP from those that are not.

Copyright $\odot 2010$ S. Karger AG, Basel

\section{Introduction}

Central precocious puberty (CPP) is due to premature activation of the hypothalamic-pituitary-gonadal (HPG) axis and can be caused by a variety of pathological condi-

Y.-M.C. and K.A.F.-S. contributed equally to this work.
Yee-Ming Chan

55 Fruit St., BHX 5

Boston, MA 02114 (USA)

Tel. +1 617726 9260, Fax +1 6177265357

E-Mailymchan@partners.org 
tions, though most cases of CPP have no identifiable cause [1]. Of the identifiable causes of CPP, the most common is a hypothalamic hamartoma: a non-tumorous, ectopic outgrowth of tissue from the base of the hypothalamus that can also cause seizures and developmental delay [2]. Hypothalamic hamartomas have been hypothesized to cause CPP by stimulating the HPG axis inappropriately early through synaptic and/or non-synaptic mechanisms, or by blocking the effects of pathways that normally inhibit the HPG axis in childhood $[1,3]$.

Several case reports have described the expression of stimulatory factors by hypothalamic hamartomas. For example, the master reproductive hormone gonadotropin-releasing hormone $(\mathrm{GnRH})$ has been shown in several studies to be expressed in hamartomas resected from children with CPP $(\mathrm{n}=8)$ [4-9]. Furthermore, Valdueza et al. [10] observed that hamartomas from three patients who had seizures but not CPP did not express GnRH. However, not all hamartoma samples from patients with CPP have been shown to express GnRH. Hamartomas from three patients with CPP were found not to express GnRH in two case reports $[8,11]$. In addition, Jung et al. [12] did not detect GnRH expression in hamartomas from two children with CPP, but instead observed expression of transforming growth factor $\alpha$ (TGF $\alpha$ ), which can stimulate release of GnRH $[13,14]$. These findings support the hypothesis that hypothalamic hamartomas may cause precocious puberty by secreting molecules that stimulate the HPG axis, but suggest that different factors are responsible in different cases.

The gene KISS1 has recently been found to encode peptides (collectively called kisspeptins) that are potent stimulators of GnRH release [15]. Signaling of kisspeptins through the G-protein-coupled receptor GPR54 (also called KISS1R) is required for normal puberty [16]. Furthermore, a gain-of-function mutation in GPR54 was identified in a girl with CPP [17]. These findings led us to examine whether the kisspeptin/GPR54 pathway is involved in the pathogenesis of CPP in patients with hypothalamic hamartomas.

A study by Parent and Matagne et al. [18] compared the gene expression profile of a hamartoma associated with CPP with those of three hamartomas from patients who did not have CPP. They identified several genes expressed at higher levels in the hamartoma associated with $\mathrm{CPP}$, and of these genes one was also found to increase across puberty in the female monkey: GRM1A, which encodes the $\alpha$ isoform of the metabotropic glutamate receptor $1(\mathrm{mGluR} 1 \alpha)[18]$.

Precocious Puberty and Hypothalamic Hamartomas
We have analyzed radiologic characteristics and examined the expression of KISS1, GnRH, TGF $\alpha$, and GRM1A in a sample of 18 hypothalamic hamartomas resected from patients with and without a history of CPP, the largest expression study of hamartoma samples reported to date. We further examined the expression of the GnRH receptor (GnRHR) and GPR54 to determine whether signaling by GnRH or kisspeptin within hypothalamic hamartomas might have a role in causing CPP.

\section{Materials and Methods}

\section{Patients}

Patients underwent resection of hypothalamic hamartomas at the Barrow Neurological Institute of St. Joseph's Hospital and Medical Center due to intractable seizures $[19,20]$. Patients were considered to have CPP if medical records noted sexual development and elevated gonadotropin levels before 8 (girls) or 9 (boys) years of age. Patients considered not to have CPP were at least 8 (girls) or 9 (boys) years old and had no history of CPP. All patients had medically refractory epilepsy, half had mental retardation, and patient $\mathrm{HH} 2013$ had features of oro-facial-digital syndrome type II (Online Mendelian Inheritance in Man 252100). All studies were approved by the Institutional Review Board of the Barrow Neurological Institute, informed consent was obtained for all subjects, and a waiver for use of de-identified tissue was granted by the Institutional Review Board of Massachusetts General Hospital.

\section{Radiologic Characterization}

All magnetic resonance imaging was evaluated by a neuroradiologist (E.C.P.) who was blind to the diagnosis of CPP. Hamartomas were typed using the classification of Delalande and Fohlen [21], with a type 4 ('giant') hamartoma defined as having a volume $>8 \mathrm{~cm}^{3}$. Volumes of hypothalamic hamartomas were determined by summing manually measured areas, multiplied by slice thickness, on sequential, contiguous, coronal $\mathrm{T}_{2}$-weighted images using Voxar 3D imaging software (DR Systems) [20]. Maximal diameter was the largest of the three diameters measured in each orthogonal plane (X-Y-Z). Hamartomas were also scored for the presence or absence of contact with the tuber cinereum and/or infundibulum, and whether the site of attachment to the hypothalamus was unilateral or bilateral.

\section{Sample Collection and Preparation}

After surgical resection, pieces of hamartoma tissue were immediately immersed in RNAlater (Applied Biosystems) and frozen for expression profiling, or fixed in 10\% formalin overnight, embedded in paraffin, and sectioned at $5 \mu \mathrm{m}$. Due to limited tissue quantity, not all hamartomas were used for all analyses.

\section{Immunohistochemistry}

Immunostaining was performed using a Ventana Benchmark XT automated immunostainer (Ventana Medical Systems, Tucson, Ariz., USA) per the manufacturer's protocol with pro- 
prietary reagents. Ventana antigen retrieval was performed for all sections. Each section was stained with a single primary antibody and counterstained with hematoxylin. Primary antibodies used were polyclonal GnRH (1:500; Abcam); GnRHR (clone A9E4) mouse monoclonal antibody (1:50, Cell Sciences); and TGF $\alpha$ rabbit polyclonal antibody (RB-9241, Lab Vision Corp.). To confirm the TGF $\alpha$ staining pattern, the TGF $\alpha$ mouse monoclonal antibody Ab-1 (Clone MF9, Lab Vision Corp.) was used on the same cohort. Sections were exposed to biocytin-labeled secondary antibodies (anti-rabbit IgG or anti-mouse IgG; 1:200) and the reaction product was visualized with standard diaminobenzidine protocols (Vector Laboratories). Negative control groups included tissue that did not express the antigen and antigen-positive sections that were processed without primary antibodies. No significant labeling was detected under the negative control conditions. Cell types were readily distinguishable by their morphology [22], and neurons $>20 \mu \mathrm{m}$ in diameter were classified as 'large'.

\section{Reverse Transcription and Quantitative Real-Time}

Polymerase Chain Reaction

Total RNA was extracted from 2-25 mg of frozen hamartoma tissue using the RNeasy Lipid kit (Qiagen), and first-strand cDNA synthesis was performed with an oligo-dT primer using the SuperScript ${ }^{\circledR}$ III First-Strand Synthesis System (Invitrogen). Total human hypothalamic RNA (Ambion) was used as a positive control. Quantitative real-time PCR was performed using the TaqMan PCR Master Mix (Applied Biosystems) with primers at 400 $\mathrm{nM}$ final concentration; primer sequences are listed in online supplementary table 1 (www.karger.com/doi/10.1159/000308162). Reactions were run on an Mx4000 Quantitative PCR System (Stratagene) with $40-50$ cycles of denaturation at $94^{\circ} \mathrm{C}$ for $30 \mathrm{~s}$ and annealing and elongation at $58^{\circ} \mathrm{C}$ for $1 \mathrm{~min}$, and the cycle threshold $\left(\mathrm{C}_{\mathrm{t}}\right)$ was determined using the accompanying software. Amplification of KISS1, GPR54, GRM1 (using a probe specific for the $\alpha$ isoform), and GAPDH was performed in triplicate. Quantitative RT-PCR performed on reactions from which reverse transcriptase was omitted did not produce a detectable signal (not shown). To determine relative expression of these genes, control cDNA was serially diluted and used to produce standard curves, which were used to convert average $C_{t}$ 's from hamartoma samples to a fold difference in mRNA abundance relative to the control RNA sample; these differences were in turn normalized to the fold difference for GAPDH relative to control.

\section{Statistics}

Fisher's two-tailed exact test was used to compare presence or absence of attachment to the tuber cinereum/infundibulum, bilateral attachment, and expression of KISS1 and GPR54 between hypothalamic hamartomas associated and not associated with CPP. Two-tailed t tests were used to compare numerical radiologic parameters and GRM1A expression levels. Hamartoma volumes and diameters and GRM1A mRNA expression levels were $\log$ transformed for analysis, as these did not exhibit normal distributions by the kurtosis/skew normality test. Linear and rankorder correlation analyses were used to compare age of puberty onset with hamartoma volume. Statistics were calculated using GraphPad Prism 4 for Windows.

\section{Results}

\section{Clinical and Radiologic Characteristics}

Characteristics of patients from whom hypothalamic hamartoma tissue was resected are summarized in table 1 . In this cohort of patients with refractory epilepsy, all types of hamartomas (using the classification of Delalande and Fohlen [21]) were found in patients both with and without a history of CPP. All 7 hamartomas in patients with CPP were found to contact the tuber cinereum and/or infundibulum (fig. 1; table 1), hypothalamic regions that contain axonal projections from endogenous GnRH neurons. In contrast, only 2 of 11 hamartomas in patients without CPP contacted these structures $(\mathrm{p}=$ 0.002 ).

Hypothalamic hamartomas associated with CPP had significantly larger volumes (geometric mean $6.6 \mathrm{~cm}^{3}$, $95 \%$ confidence interval [CI] $2.7-15.9 \mathrm{~cm}^{3}$ ) than those not associated with CPP (geometric mean $1.1 \mathrm{~cm}^{3}, 95 \% \mathrm{CI}$ $0.5-2.2 \mathrm{~cm}^{3}, \mathrm{p}=0.002$ ). They also had significantly larger maximal diameters (geometric mean [95\% CI] 20.2 $\mathrm{mm}$ [14.8-27.6] in CPP group, 11.7 [8.9-15.3] in no CPP group, $\mathrm{p}=0.008$ ). Hamartomas associated with $\mathrm{CPP}$ were more likely to have bilateral attachment to the hypothalamus ( $p=0.01)$; differences in the size of the base of attachment were not statistically significant (mean \pm SEM $1.26 \pm 0.25$ vs. $0.74 \pm 0.13 \mathrm{~mm}^{2}, \mathrm{p}=0.1$ ). There was no correlation between hamartoma volume and age at diagnosis of precocious puberty ( $\mathrm{p} \geq 0.86$ by linear and rankorder correlation analyses).

\section{Expression of $G n R H$}

$\mathrm{GnRH}$ expression was detected in all hypothalamic hamartomas, both those associated and those not associated with CPP ( $\mathrm{n}=13$; table 2$)$. Moderate immunostaining was present in a predominantly nuclear pattern in $\sim 50 \%$ of small neurons ( $<20 \mu \mathrm{m}$ diameter) and $\sim 70 \%$ of large neurons (fig. 2a); large neurons also exhibited staining in cell bodies. Weak glial staining was observed in two samples (data not shown). The neuropil also showed weak to moderate immunoreactivity in all cases.

\section{Expression of TGF $\alpha$}

TGF $\alpha$ expression was also observed in all hypothalamic hamartomas studied ( $\mathrm{n}=14$; table 2$)$. About half of neurons, both large and small, exhibited immunoreactivity primarily in cell bodies (fig. 2b). Nearly all glial cells exhibited strong immunoreactivity in both cellbody and nuclear patterns. The neuropil exhibited little 
Table 1. Clinical and radiologic characteristics

\begin{tabular}{|c|c|c|c|c|c|c|c|c|c|}
\hline Patient & Sex & $\begin{array}{l}\text { Age at } \\
\text { surgery } \\
\text { years }\end{array}$ & $\begin{array}{l}\text { Age at } \\
\text { puberty } \\
\text { years }\end{array}$ & Type & $\begin{array}{l}\text { Attachment to } \\
\text { tuber cinereum/ } \\
\text { infundibulum }\end{array}$ & $\begin{array}{l}\text { Maximal } \\
\text { diameter } \\
\mathrm{mm}\end{array}$ & $\begin{array}{l}\text { Area of } \\
\text { attachment } \\
\text { base, } \mathrm{mm}^{2}\end{array}$ & $\begin{array}{l}\text { Volume } \\
\mathrm{cm}^{3}\end{array}$ & $\begin{array}{l}\text { Site of } \\
\text { attach- } \\
\text { ment }\end{array}$ \\
\hline \multicolumn{10}{|l|}{$C P P$} \\
\hline 2092 & $\mathrm{M}$ & 1.1 & 0.8 & 3 & + & 18.0 & 1.30 & 4.49 & $\mathrm{~L}$ \\
\hline 2027 & M & 2.5 & 2.0 & 3 & + & 16.6 & 0.95 & 3.91 & B \\
\hline 2017 & $\mathrm{M}$ & 4.8 & 3.2 & 1 & + & 13.8 & 0.27 & 2.46 & $\mathrm{R}$ \\
\hline 2021 & M & 11.3 & 1.0 & 2 & + & 14.9 & 1.36 & 2.56 & B \\
\hline 2008 & $\mathrm{M}$ & 13.8 & 6.5 & 4 & + & 30.6 & 1.84 & 15.70 & B \\
\hline 2079 & $\mathrm{~F}$ & 11.6 & 0.6 & 4 & + & 30.9 & 2.28 & 28.28 & B \\
\hline 2062 & $\mathrm{~F}$ & 19.3 & 6.0 & 4 & + & 23.9 & 0.84 & 11.19 & B \\
\hline \multicolumn{10}{|l|}{ No CPP } \\
\hline 2094 & M & 9.5 & $\mathrm{~N} / \mathrm{A}$ & 2 & - & 8.4 & 0.30 & 0.38 & $\mathrm{~L}$ \\
\hline 2077 & $\mathrm{M}$ & 11.2 & $13^{\mathrm{a}}$ & 2 & - & 7.7 & 0.48 & 0.38 & $\mathrm{R}$ \\
\hline 2088 & M & 12.8 & $12^{\mathrm{a}}$ & 2 & - & 7.4 & 0.36 & 0.31 & $\mathrm{~L}$ \\
\hline 2065 & $\mathrm{M}$ & 13.3 & $\mathrm{~N} / \mathrm{A}$ & 2 & - & 13.8 & 1.03 & 1.75 & $\mathrm{R}$ \\
\hline 2081 & M & 13.8 & $15^{\mathrm{a}}$ & 2 & - & 14.4 & 1.15 & 1.70 & $\mathrm{~L}$ \\
\hline 2051 & $\mathrm{~F}$ & 9.2 & $9^{b}$ & 2 & - & 9.5 & 0.54 & 0.56 & $\mathrm{R}$ \\
\hline 2050 & $\mathrm{~F}$ & 10.5 & $12^{\mathrm{c}}$ & 2 & - & 9.1 & 0.46 & 0.45 & $\mathrm{~L}$ \\
\hline 2080 & $\mathrm{~F}$ & 11.8 & $\mathrm{~N} / \mathrm{A}$ & 1 & + & 19.6 & 1.40 & 5.00 & $\mathrm{~L}$ \\
\hline 2015 & $\mathrm{~F}$ & 13.3 & N/A & 1 & - & 9.5 & 0.17 & 0.64 & $\mathrm{R}$ \\
\hline 2025 & $\mathrm{~F}$ & 17.4 & $12^{\mathrm{c}}$ & 3 & - & 14.1 & 1.20 & 2.02 & $\mathrm{R}$ \\
\hline 2013 & $\mathrm{~F}$ & 19.5 & $14^{\mathrm{c}}$ & 4 & + & 25.4 & 1.04 & 8.15 & B \\
\hline
\end{tabular}

$\mathrm{CPP}=$ Central precocious puberty; N/A = not available; $\mathrm{L}=$ left; $\mathrm{R}=$ right; $\mathrm{B}=$ bilateral. Hamartoma type is according to the classification of Delalande and Fohlen [21]: type 1, subhypothalamic; type 2, intraventricular; type 3, both subhypothalamic and intraventricular; type 4, 'giant' hamartoma, here defined as volume $>8 \mathrm{~cm}^{3}$.

${ }^{a}$ Voice change. ${ }^{b}$ Breast development. ${ }^{c}$ Menarche.

to no staining. Because the nuclear staining pattern was unexpected, immunostaining was repeated and confirmed with a second antibody against TGF $\alpha$ (data not shown).

\section{Expression of the GnRH Receptor}

Like GnRH and TGF $\alpha$, the GnRH receptor was expressed in all hypothalamic hamartoma tissues studied ( $\mathrm{n}=13$; table 2; fig. 2c), largely in the cell bodies of both large and small neurons. No staining was seen in glial cells, and moderate neuropil or background staining was present in all samples.

\section{Expression of KISS1 and GPR54}

Due to the lack of availability of antibodies against human kisspeptin, we examined expression of KISS1 by reverse transcription-polymerase chain reaction (RTPCR). Quantitative RT-PCR of cDNA prepared from hamartoma tissue revealed expression of KISS1 mRNA in 1 of 7 samples from children with CPP and 1 of 11 samples from patients with no history of CPP (table 2; $\mathrm{p}=1$ by Fisher's exact test). We also examined expression of GPR54 in hypothalamic hamartomas using RTPCR. Like KISS1, GPR54 message was detectable in only some hamartomas and was seen in hamartomas that were both associated and not associated with CPP (table $2 ; \mathrm{p}=0.32$ ).

\section{Expression of GRM1A}

We examined GRM1A expression in our cohort by quantitative RT-PCR. GRM1A levels were higher in the CPP group, but this difference was not statistically significant (table 2; geometric mean [95\% CI] of expression relative to control $0.61[0.13-2.90]$ in CPP group, 0.19 [0.08-0.45] in no CPP group, $\mathrm{p}=0.1)$. 
Fig. 1. Radiologic features. a, b Axial images from patient $\mathrm{HH} 2017$ (a), who had a history of CPP, and patient HH2015 (b), who did not have a history of CPP. Both images are $\mathrm{T}_{2}$-weighted fast spin-echo (TR/TE 4900/85 and 3600/72, respectively) with $2 \mathrm{~mm}$ slice thickness and $2 \mathrm{~mm}$ spacing. Asterisks mark hypothalamic hamartomas (medium intensity), each arrow marks the infundibulum (low to medium signal intensity and annular shape, with the central, fluid-filled infundibular recess showing high signal intensity), and arrowheads in $\mathbf{b}$ mark a line of high signal intensity indicating fluid between the hypothalamic hamartoma and the infundibulum. c Hamartoma volumes. Bars indicate geometric means. d Contact with the tuber cinereum and/or infundibulum (median eminence).
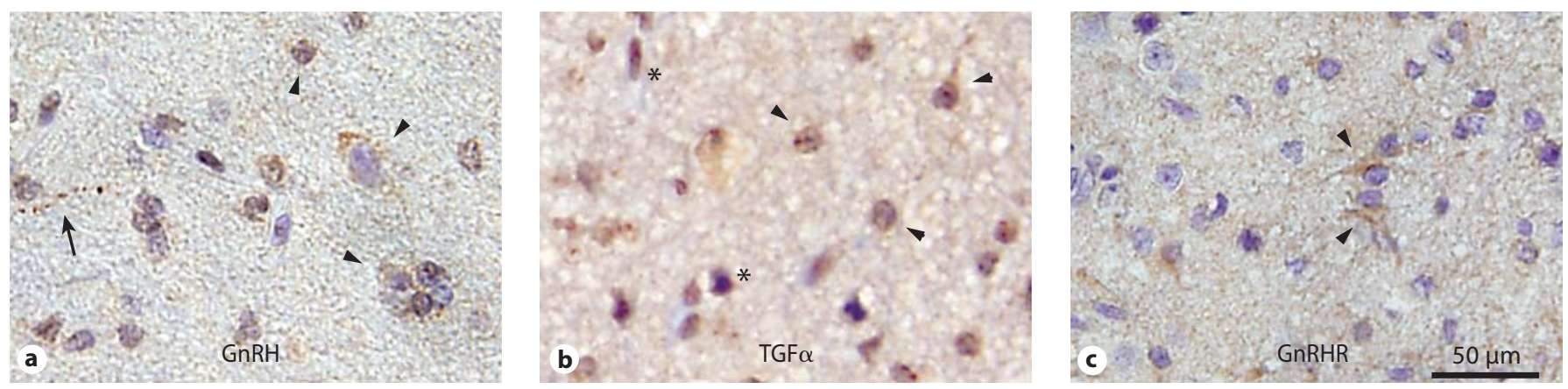

Fig. 2. Representative immunostaining of hypothalamic hamartoma tissue for a GnRH staining in HH2021, b TGF $\alpha$ staining in HH2025, and c GnRHR staining in HH2092. Arrowheads = examples of immunopositive neurons; arrow = immunopositive neuronal fiber; asterisks = immunopositive glia.

\section{Discussion}

To our knowledge this is the largest series of hypothalamic hamartomas studied for expression of potential stimulatory factors that may contribute to the pathogenesis of CPP, namely, GnRH, GnRHR, TGF $\alpha$, and KISS1,
GPR54, and GRM1A. Our principal findings are: (1) association of CPP with larger hamartoma size and contact with critical hypothalamic structures (the infundibulum and tuber cinereum), consistent with previous studies of patients with hypothalamic hamartomas and seizures $[23,24]$; (2) expression of GnRH and TGF $\alpha$ in all hamar- 
tomas analyzed, regardless of the patient's history of CPP; and (3) limited expression of KISS1 and GPR54 that also did not correlate with CPP.

Our results confirm and extend the findings in a recent study by Parent and Matagne et al. [18] of five hypothalamic hamartomas, two from patients with CPP. Expression of GNRH1 and TGFA was seen in all five hamartomas, KISS1 expression in none, and GPR54 expression in one of the two hamartomas associated with CPP and two of the three hamartomas not associated with CPP. Our collective results indicate that, despite their potent stimulatory properties, expression of $\mathrm{GnRH}, \mathrm{TGF} \alpha$, or kisspeptin alone is not sufficient for a hypothalamic hamartoma to cause CPP. Indeed, the limited expression of KISS1 and GPR54 in our series suggests that kisspeptin signaling is unlikely to contribute to the pathogenesis of CPP in most cases.

Rather, we found that anatomic features better distinguished hamartomas that were associated with CPP from those that were not. Both larger size and contact with the infundibulum/tuber cinereum were associated with CPP in our series. However, large hamartoma size does not appear to be a prerequisite for causing CPP, as other series have reported small hypothalamic hamartomas in patients with CPP. In particular, Debeneix et al. [25] found that patients with CPP without seizures (a population not studied in our cohort) had smaller hamartomas than patients with seizures, whether with or without CPP. Together, these findings suggest that a hamartoma's anatomic contacts may determine whether it causes CPP, and in patients with seizures larger hamartomas are more likely to have these critical contacts.

We identified two large hamartomas that contacted the infundibulum yet were not associated with CPP. At least one of these hamartomas expressed both GnRH and TGF $\alpha$ (the other had no fixed tissue available for analysis). Freeman et al. [24] also reported examples of hamartomas contacting the infundibulum that were not associated with precocious puberty. It is possible that these hamartomas lacked functional connections with target tissues despite their anatomic proximity. Alternatively, the hamartoma may have impaired the function of the HPG axis, secreting stimulatory factors yet blocking their downstream effects; notably, however, one of the patients had puberty at a normal age prior to surgery. Further study of hamartomas that contact the infundibulum yet are not associated with CPP will refine our understanding of how hypothalamic hamartomas cause CPP.

The report by Parent and Matagne et al. [18] featured microarray analysis to compare gene expression profiles
Table 2. Expression patterns in hypothalamic hamartomas

\begin{tabular}{llllllll}
\hline Patient & Sex & GnRH & TGF $\alpha$ & GnRHR & KISS1 & GPR54 & GRM1A \\
\hline CPP & & & & & & & \\
2092 & $\mathrm{M}$ & + & + & + & - & 0.34 & $\mathrm{ND}$ \\
2027 & $\mathrm{M}$ & + & + & + & - & - & $\mathrm{ND}$ \\
2017 & $\mathrm{M}$ & + & + & + & - & - & 1.50 \\
2021 & $\mathrm{M}$ & + & + & + & 0.05 & - & 0.28 \\
2008 & $\mathrm{M}$ & + & + & + & - & - & 0.48 \\
2079 & $\mathrm{~F}$ & + & + & + & - & - & 3.08 \\
2062 & $\mathrm{~F}$ & + & + & + & - & - & 0.14 \\
\hline No CPP & & & & & & & \\
2094 & $\mathrm{M}$ & + & + & + & - & 0.87 & 0.59 \\
2077 & $\mathrm{M}$ & $\mathrm{ND}$ & $\mathrm{ND}$ & $\mathrm{ND}$ & - & 1.90 & 0.78 \\
2088 & $\mathrm{M}$ & + & + & + & - & 0.01 & $\mathrm{ND}$ \\
2065 & $\mathrm{M}$ & $\mathrm{ND}$ & $\mathrm{ND}$ & $\mathrm{ND}$ & - & 0.03 & 0.39 \\
2081 & $\mathrm{M}$ & + & + & + & - & 0.15 & 0.05 \\
2051 & $\mathrm{~F}$ & $\mathrm{ND}$ & $\mathrm{ND}$ & $\mathrm{ND}$ & 0.31 & - & 0.11 \\
2050 & $\mathrm{~F}$ & $\mathrm{ND}$ & $\mathrm{ND}$ & $\mathrm{ND}$ & - & - & 0.04 \\
2080 & $\mathrm{~F}$ & + & + & + & - & - & 0.69 \\
2015 & $\mathrm{~F}$ & + & + & + & - & - & 0.50 \\
2025 & $\mathrm{~F}$ & + & + & + & - & - & 0.06 \\
2013 & $\mathrm{~F}$ & $\mathrm{ND}$ & $\mathrm{ND}$ & $\mathrm{ND}$ & - & - & 0.08 \\
\hline Control & & & & & 1 & 1 & 1 \\
\end{tabular}

Expression of GnRH, TGF $\alpha$, and GnRHR was assessed by immunohistochemistry; expression of KISS1, GPR54, and GRM1A was assessed by quantitative RT-PCR. Expression levels of mRNA were calculated relative to $G A P D H$ and normalized to control cDNA synthesized from total RNA from human male hypothalamus (Ambion). $\mathrm{CPP}=$ Central precocious puberty; $+=$ expression present; $\mathrm{ND}=$ not determined; $-=$ no amplification .

between a hamartoma associated with CPP and three hamartomas not associated with CPP. Of the genes expressed at a higher level in the hypothalamic hamartoma associated with precocious puberty, GRM1A also exhibited increasing levels of expression in female rhesus macaques across puberty. In contrast, we did not observe a significant difference in mean GRM1A levels between hamartomas from patients with and without a history of CPP. However, two hamartomas associated with CPP in our series (HH2017 and HH2079) had GRM1A levels higher than the $95 \%$ CI of hamartomas not associated with CPP (table 2). Thus, elevated GRM1A expression may play a role in the pathogenesis of CPP in a subset of hamartomas. An alternative possibility suggested by Parent and Matagne et al. [18] is that expression of GRM1A may have been transiently elevated in some hamartomas and was no longer elevated at the time of resection. Tech- 
nically, it is also possible that normal tissue may have been present in some hamartoma samples, resulting in inaccurate measurement of GRM1A expression. Further examination of GRM1A expression in hypothalamic hamartomas will help to elucidate its role in the pathogenesis of CPP.

As stated earlier, hypothalamic hamartomas have been hypothesized to cause CPP by stimulating the HPG axis or by interfering with inhibitory pathways that restrain the HPG axis in childhood. While our study focused on stimulatory factors, our results do not exclude the latter possibility. Indeed, patients have been described to develop CPP after resection of their hypothalamic hamartomas, even when the resection appeared to be complete [e.g., 18]. The emergence of CPP after surgery could be due to surgical disruption of inhibitory pathways. Alternatively, posttraumatic activation of glial cells could lead to production of stimulatory factors such as TGF $\alpha$ [14].

In summary, we have used a unique collection of hypothalamic hamartoma tissue to examine expression of molecules that activate the reproductive endocrine axis. Contrary to our initial hypothesis that these molecules would be expressed exclusively in hamartomas associated with CPP, we found no correlation between CPP and expression of these molecules. Instead, we found significant correlation between anatomic features of the hamartomas and CPP. As we enter the era of gene-expression profiling for the prognosis and treatment of tumors [26], our results serve as a reminder that anatomic and functional characteristics remain important determinants of the clinical consequences of masses, particularly in the brain. Based on histopathological [22], ultrastructural [27], electrophysiological $[19,28]$, and now endocrine characterization of hypothalamic hamartomas resected at the Barrow Neurological Institute, we believe that the clinical consequences of these lesions are not simply due to mass effects. Rather, hypothalamic hamartomas are intrinsically active masses, with their effects determined by functional connections with critical brain regions: the tuber cinereum/infundibulum to cause precocious puberty and other regions, possibly the mammillary bodies [24], to cause seizures.

\section{Acknowledgements}

We thank Douglas Hayden for statistical advice and members of the Massachusetts General Hospital Reproductive Endocrine Unit for valuable discussions. This work was supported by the US Eunice Kennedy Shriver National Institute of Child Health and Human Development (grant U54 HD 028138) and the Barrow Neurological Foundation. Y.-M.C. received support from the US NICHD (grants T32 HD 07369 and F32 HD 056759) and a Novo Nordisk Lawson Wilkins Pediatric Endocrine Society Research Fellowship Award.

\section{References}

1 Grumbach MM, Styne DM: Puberty: ontogeny, neuroendocrinology, physiology, and disorders; in Kronenberg HM, Melmed S, Polonsky KS, Larsen PR (eds): Williams Textbook of Endocrinology, ed 11. Philadelphia, Saunders Elsevier, 2008, pp 9691166.

-2 Jung H, Parent AS, Ojeda SR: Hypothalamic hamartoma: a paradigm/model for studying the onset of puberty. Endocr Dev 2005;8:8193.

-3 Arita K, Kurisu K, Kiura Y, Iida K, Otsubo H: Hypothalamic hamartoma. Neurol Med Chir (Tokyo) 2005;45:221-231.

$\checkmark 4$ Judge DM, Kulin HE, Page R, Santen R, Trapukdi S: Hypothalamic hamartoma: a source of luteinizing-hormone-releasing factor in precocious puberty. N Engl J Med 1977;296:7-10.

5 Hochman HI, Judge DM, Reichlin S: Precocious puberty and hypothalamic hamartoma. Pediatrics 1981;67:236-244.
-6 Price RA, Lee PA, Albright AL, Ronnekleiv OK, Gutai JP: Treatment of sexual precocity by removal of a luteinizing hormone-releasing hormone secreting hamartoma. JAMA 1984;251:2247-2249.

7 Culler FL, James HE, Simon ML, Jones KL: Identification of gonadotropin-releasing hormone in neurons of a hypothalamic hamartoma in a boy with precocious puberty Neurosurgery 1985;17:408-412.

8 Inoue HK, Kanazawa H, Kohga H, Zama A, Ono N, Nakamura M, Ohye C: Hypothalamic hamartoma: anatomic, immunohistochemical and ultrastructural features. Noshuyo Byori 1995;12:45-51.

9 Akai T, Okamoto K, Iizuka H, Kakinuma H, Nojima T: Treatments of hamartoma with neuroendoscopic surgery and stereotactic radiosurgery: a case report. Minim Invasive Neurosurg 2002;45:235-239.
10 Valdueza JM, Cristante L, Dammann O, Bentele K, Vortmeyer A, Saeger W, Padberg B, Freitag J, Herrmann HD: Hypothalamic hamartomas: with special reference to gelastic epilepsy and surgery. Neurosurgery 1994; 34:949-958.

11 Markin RS, Leibrock LG, Huseman CA, McComb RD: Hypothalamic hamartoma: a report of two cases. Pediatr Neurosci 1987;13: 19-26.

12 Jung H, Carmel P, Schwartz MS, Witkin JW, Bentele KH, Westphal M, Piatt JH, Costa ME, Cornea A, Ma YJ, Ojeda SR: Some hypothalamic hamartomas contain transforming growth factor $\alpha$, a puberty-inducing growth factor, but not luteinizing hormonereleasing hormone neurons. J Clin Endocrinol Metab 1999;84:4695-4701.

13 Ojeda SR, Urbanski HF, Costa ME, Hill DF, Moholt-Siebert M: Involvement of transforming growth factor $\alpha$ in the release of luteinizing hormone-releasing hormone from the developing female hypothalamus. Proc Natl Acad Sci USA 1990;87:9698-9702. 
- 14 Junier MP, Ma YJ, Costa ME, Hoffman G, Hill DF, Ojeda SR: Transforming growth factor $\alpha$ contributes to the mechanism by which hypothalamic injury induces precocious puberty. Proc Natl Acad Sci USA 1991; 88:9743-9747.

-15 Kauffman AS, Clifton DK, Steiner RA: Emerging ideas about kisspeptin - GPR54 signaling in the neuroendocrine regulation of reproduction. Trends Neurosci 2007;30: 504-511.

16 Herbison AE: Genetics of puberty. Horm Res 2007;68(suppl 5):75-79.

17 Teles MG, Bianco SD, Brito VN, Trarbach EB, Kuohung W, Xu S, Seminara SB, Mendonca BB, Kaiser UB, Latronico AC: A GPR54-activating mutation in a patient with central precocious puberty. N Engl J Med 2008;358:709-715.

- 18 Parent AS, Matagne V, Westphal M, Heger S, Ojeda S, Jung H: Gene expression profiling of hypothalamic hamartomas: a search for genes associated with central precocious puberty. Horm Res 2008;69:114-123.
19 Wu J, Xu L, Kim DY, Rho JM, St John PA, Lue LF, Coons S, Ellsworth K, Nowak L, Johnson E, Rekate H, Kerrigan JF: Electrophysiological properties of human hypothalamic hamartomas. Ann Neurol 2005;58:371-382.

20 Ng Y.-t., Rekate HL, Prenger EC, Chung SS Feiz-Erfan I, Wang NC, Varland MR, Kerrigan JF: Transcallosal resection of hypothalamic hamartoma for intractable epilepsy. Epilepsia 2006;47:1192-1202.

-21 Delalande O, Fohlen M: Disconnecting surgical treatment of hypothalamic hamartoma in children and adults with refractory epilepsy and proposal of a new classification. Neurol Med Chir (Tokyo) 2003;43:61-68.

$>22$ Coons SW, Rekate HL, Prenger EC, Wang N, Drees C, Ng Y.-t., Chung SS, Kerrigan JF: The histopathology of hypothalamic hamartomas: study of 57 cases. J Neuropathol Exp Neurol 2007;66:131-141.

23 Jung H, Neumaier Probst E, Hauffa BP, Partsch C-J, Dammann O: Association of morphological characteristics with precocious puberty and/or gelastic seizures in hypothalamic hamartoma. J Clin Endocrinol Metab 2003;88:4590-4595.

-24 Freeman JL, Coleman LT, Wellard RM, Kean MJ, Rosenfeld JV, Jackson GD, Berkovic SF, Harvey AS: MR imaging and spectroscopic study of epileptogenic hypothalamic hamartomas: analysis of 72 cases. Am J Neuroradiol 2004;25:450-462.
25 Debeneix C, Bourgeois M, Trivin C, SainteRose C, Brauner R: Hypothalamic hamartoma: comparison of clinical presentation and magnetic resonance images. Horm Res 2001;56:12-18.

26 Van't Veer LJ, Bernards R: Enabling personalized cancer medicine through analysis of gene-expression patterns. Nature 2008;452: 564-570.

27 Beggs J, Nakada S, Fenoglio K, Wu J, Coons S, Kerrigan JF. Hypothalamic hamartomas associated with epilepsy: ultrastructural features. J Neuropathol Exp Neurol 2008;67: 657-668.

-28 Wu J, Chang Y, Li G, Xue F, DeChon J, Ellsworth K, Liu Q, Yang K, Bahadroani N, Zheng C, Zhang J, Rekate H, Rho JM, Kerrigan JF: Electrophysiological properties and subunit composition of $\mathrm{GABA}_{\mathrm{A}}$ receptors in patients with gelastic seizures and hypothalamic hamartoma. J Neurophysiol 2007;98: 5-15. 